\title{
The Association of Cardiovascular Responses with Brain c-fos Expression after Central Carbachol in the Near-Term Ovine Fetus
}

\author{
Lijun Shi', ${ }^{1,2}$ Yuying Zhang', Paul Morrissey ${ }^{2}$, Jiaming $\mathbf{Y a o}^{2}$ and Zhice $\mathbf{X u}^{*, 1,2}$ \\ 'Perinatal Research Laboratory, Soochow University School of Medicine, Suzhou, China; ${ }^{2}$ Harbor-UCLA Medical Center Research \& Education \\ Institute, Torrance, CA, USA
}

\begin{abstract}
Central cholinergic mechanisms play important roles in the control of cardiovascular responses. However, in utero development of brain cholinergic mechanism in regulation of arterial pressure before birth is largely unknown. This study investigated cardiovascular responses to central application of carbachol in fetuses and determined functional development of the central cholinergic systems controlling fetal pressor responses in utero. Chronically prepared near-term ovine fetuses ( $90 \%$ gestation) received an injection of carbachol intracerebroventricularly (i.c.v.). Fetal cardiovascular responses were measured, and the brains were used for c-fos mapping studies. In response to carbachol injection i.c.v., fetal systolic, diastolic, and mean arterial pressure (MAP) immediately increased, accompanied by a bradycardia. The maximum increase of MAP was at $30 \mathrm{~min}$ after the i.c.v. injection of carbachol and lasted 90 min. Associated with the pressor response, the neuronal activity marked with c-fos was enhanced significantly in the fetal anterior third ventricle (AV3V) region (including the median preoptic nucleus and organum vasculosum of the lamina terminalis) in the forebrain, and in the area postrema, lateral parabrachial nucleus, nucleus tractus solitary, and rostral ventrolateral medulla in the hindbrain. These results indicate that the central cholinergic mechanism is functional in the control of fetal blood pressure at the last third of gestation, and the central AV3V region and hindbrain have been intact relatively during in utero development in sheep at $90 \%$ gestational stage. Neuropsychopharmacology (2005) 30, 2 I62-2168. doi:I0.1038/sj.npp. 1300738; published online 20 April 2005
\end{abstract}

Keywords: developmental neurobiology; hypertension; cardiovascular; neurotransmitters

\section{INTRODUCTION}

Central cholinergic mechanisms play important roles in the control of cardiovascular responses (Fitzsimons, 1972; Hoffman et al, 1977; Grossman, 1960; Stone et al, 1992). Central application of carbachol, a nonselective cholinergic agonist, produces an increase of blood pressure (BP), vasopressin release, and drinking (Barbosa et al, 1995; litake et al, 1986; Mahon et al, 1995; Poole, 1983). However, investigation of the development of brain cholinergic systems and their roles in cardiovascular homeostasis in utero has been very limited. Progress has been made in demonstrating that programming during early development may impact on BP in later life (Vehaskari et al, 2001). In addition, it is known that nicotine, another cholinergic agent, can enter

* Correspondence: $\operatorname{Dr} \mathrm{Z}$ Xu, School of Medicine, University of California at Los Angeles, 626 Madrid Ave, Torrance, CA 9050I, USA, Tel: + I 310320 6420, E-mail: zxuhice@ucla.edu

Received 10 January 2005; revised and accepted 22 February 2005 Online publication: 7 March 2005 at http://www.acnp.org/citations/ NPP0307050500 I7/default.pdf fetuses via mothers exposed to smoking (Onal et al, 2004; Oncken et al, 2003). Therefore, it is important to investigate the functional development of central cholinergic mechanisms controlling fetal cardiovascular homeostasis.

Central nervous system (CNS) contains extensive cholinergic components (Mahon et al, 1995). The most important of these are thought to be certain in the anterior third ventricle $(\mathrm{AV} 3 \mathrm{~V})$ region and hindbrain (Mahon et al, 1995; Brezenoff and Giuliano, 1982; $\mathrm{Xu}$ et al, 2001b). Among these structures, the AV3V is one of the most important areas in the forebrain in cardiovascular regulation (Brody et al, 1978; Brody and Johnson, 1980). Experiments using microinjections, lesions, immediate early genes, and recording unit activity identified the nuclei located in the AV3V, including the organum vasculosum of the lamina terminalis (OVLT) and the median preoptic nucleus (MnPO), to be the major areas for central carbachol-mediated cardiovascular responses (Brody and Johnson, 1980; Fuller, 1984; Johnson and Thunhorst, 1997). The integrity of the AV3V region is essential for pressor responses by central cholinergic activation. In addition to the well-characterized 
roles of these forebrain structures, accumulating evidence showed that hindbrain sites (eg the nucleus tractus solitary (NTS) and the rostral ventrolateral medulla (RVLM)) are also involved in central cholinergically mediated cardiovascular responses (Gurtu et al, 1986; Kubo et al, 1995). Despite this information, it is noted that all those data are obtained from animals after birth. In study of fetal cholinergic mechanisms controlling cardiovascular functions, previous studies have focused exclusively on the peripheral sides (Nawayhid et al, 1975). Few data exist characterizing the in utero functional development of central cholinergic systemsmediated cardiovascular regulation before birth. The early work using autoradiographic methods has shown that brain cholinergic systems are present in the fetus (Kinney et al, 1993, 1995). One study tried to connect central cholinergic effects with fetal BP by using intravenous injection of cholinergic drugs (Szeto and Hinman, 1990). However, the agonist injected in the vein also acts on the peripheral system so that it is difficult and complicated in analysis of the central effects. In fact, there has been no data on cholinergic actions inside the fetal brain in utero.

The present study, therefore, was designed to determine (1) fetal cardiovascular responses induced by central carbachol; (2) the carbachol action sites in the developing fetal brain. Information gained increases our understanding of the development of central cholinergic mechanisms controlling cardiovascular homeostasis and provides new evidence for the functional development of brain cholinergic network in the early stage of life.

\section{MATERIALS AND METHODS}

\section{Animals and Surgical Preparation}

Time-dated pregnant ewes with singleton fetuses (gestational age $130 \pm 3$, term $\sim 145$ days) were used. The sheep were housed indoors in individual steel study cages and acclimated to a $12: 12$-h light-dark period. Both feed (alfalfa pellets) and water were provided ad libitum, except for the last $24 \mathrm{~h}$ before surgery, when feed was withheld.

Anesthesia was induced by an intramuscular injection of ketamine hydrochloride $(20 \mathrm{mg} / \mathrm{kg})$ plus atropine sulfate $(50 \mu \mathrm{g} / \mathrm{kg})$ and was maintained by maternal endotracheal ventilation with $11 / \mathrm{min}$ oxygen and $3 \%$ isoflurane. Polyethylene catheters $(\mathrm{ID}=1.8 \mathrm{~mm}, \mathrm{OD}=2.3 \mathrm{~mm}$ ) were inserted into a maternal femoral vein and artery and advanced into the inferior vena cava and abdominal aorta, respectively. The uterus was exposed by a midline abdominal incision, and a small hysterotomy was performed to provide access to fetal hindlimbs. Polyethylene catheters ( $\mathrm{ID}=1.0 \mathrm{~mm}, \mathrm{OD}=1.8 \mathrm{~mm}$ ) were inserted into the femoral vein and artery. An intrauterine catheter was inserted for measuring amniotic fluid pressure. A second uterine incision exposed the fetal head. An intracranial cannula (18 gauge) was placed in the lateral ventricle and immobilized with dental cement with the assistance of two stainless steel screws affixed in the fetal skull. Patency of the catheter at insertion was assessed by free flow of cerebrospinal fluid via gravity drainage. The uterine incisions were closed in layers. All catheters were passed through a subcutaneous tunnel and exteriorized through a small incision on the ewe's flank and placed in a cloth pouch.

At least 5 days of postoperative recovery were allowed before experimental studies. Antibiotics were administered intravenously twice daily to the ewe ( $72 \mathrm{mg}$ gentamicin, $1 \mathrm{~g}$ oxacillin, and $1 \mathrm{~g}$ chloramphenicol) and to the fetus (8 $\mathrm{mg}$ gentamicin and $33 \mathrm{mg}$ oxacillin) during the first 2 days postsurgery.

\section{Experimental Protocol}

All experiments were performed on conscious animals standing in their holding cages, with food and water provided ad libitum. Studies began with a baseline study period $(-60-0 \mathrm{~min})$ followed by experimental study period $(0-120 \mathrm{~min})$ in two groups (control: $n=5$; experimental: $n=5)$. Beginning at time 0 , carbachol $(3 \mu \mathrm{g} / \mathrm{kg}$, Sigma $)$ in isotonic saline $(1 \mathrm{ml})$ was injected intracerebroventricularly (i.c.v.) into the fetus over $5 \mathrm{~min}$. Injection concentrations were based on estimated fetal body weight (FBW) (Robillard et al, 1979). To the control animals, isotonic saline (vehicle) was injected. Throughout the study, maternal and fetal systolic and diastolic pressure, amniotic fluid pressure, and heart rate were monitored continuously. The fetal mean arterial pressure (MAP) was corrected for amniotic cavity pressure. Maternal and fetal blood samples were withdrawn from the fetal and maternal arterial catheter for the measurements of blood $\mathrm{PO}_{2}, \mathrm{PCO}_{2}$, hemoglobin, and $\mathrm{pH}$ on a Radiometer BM 33 MK2-PHM 72 MKS acid-base analyzer system (Radiometer, Copenhagan) adjusted to sheep internal temperature $\left(39^{\circ} \mathrm{C}\right)$.

\section{Immunohistochemistry Experiments}

At the conclusion of the study, the animals were anesthetized and ventilated with a mixture of isoflurane and oxygen as described. A middle abdominal incision was made and the fetal head and neck were exposed. A 16-gauge needle was inserted into the fetal carotid artery for perfusion with $0.01 \mathrm{M}$ phosphate-buffered saline followed by $4 \%$ paraformaldehyde. Postfixation was performed in the paraformaldehyde solution for $12 \mathrm{~h}$, after which the brain was placed in $20 \%$ sucrose overnight. Coronal sections (20 ím) were cut through the fetal forebrain and hindbrain on a cryostat. Every other section of the OVLT, MnPO, and every third section of the NTS, the lateral parabrachial nuclei (LPBN), the area postrema (AP), and the rostral ventrolateral medullar (RVLM) in the hindbrain were used for $c$-fos immunoreactivity (FOS-ir) staining using the avidinbiotin-peroxidase technique. The tissue sections were incubated on a gentle shaker overnight at $4{ }^{\circ} \mathrm{C}$ in the primary antibody $(1: 15000$, Santa Cruz Biotechnology, Santa Cruz, CA). The polyclone FOS primary antibody has been raised from rabbits against the $\mathrm{N}$-terminal sequence of the FOS protein. The sections were further incubated in a goat anti-rabbit serum $(1: 400)$ for $1 \mathrm{~h}$ and then processed using the Vectastain $\mathrm{ABC}$ kit for $1 \mathrm{~h}$ (Vector Labs, Burlingame, CA) at room temperature. The sections were then treated with $1 \mathrm{mg} / \mathrm{ml}$ diaminobenzidine tetrahydrochloride (Sigma) $(0.02 \%$ hydrogen peroxide). All 
sections were mounted on slides, dehydrated in alcohol, and then coverslipped.

\section{Data Analysis}

Fetal and maternal BP and amniotic fluid pressure were monitored with a Beckman R-612 (Beckman Instruments, Fullerton, CA) physiological recorder with Statham (Garret, Oxnard, CA) P23 pressure transducers. BP and heart rate were determined by computer analysis of waveforms utilizing a customized pattern recognition algorithm. All signals in cardiovascular studies were digitized at $500 \mathrm{~Hz}$ and recorded on a computer with Win-DAQ acquisition software (Data Q instruments, Akron, OH). Heart rate, systolic and diastolic pressure, and MAP were calculated from the pressure waveforms by means of Advanced CODAS software.

The number of FOS-ir-positive cells in the brain was evaluated in a qualitative and blinded manner as reported (Xu et al, 2001a). The number of FOS-ir-positive cells in the OVLT and the MnPO was counted. The MnPO was divided as the dorsal and ventral MnPO by the anterior commissure, and the number of positive FOS-ir was counted in both parts. FOS-ir was also counted in the NTS, AP, RVLM, and LPBN in the hindbrain. A repeated measures ANOVA was used to determine differences over time and effects of the treatments. Comparison before and after the treatments was determined with one-way ANOVA followed by the Tukey post hoc test or Student's $t$-test. All data were expressed as mean \pm SEM. Statistic significance was accepted at $p<0.05$.

\section{RESULTS}

\section{Blood Values}

For both the control and experimental animals, i.c.v. injection of carbachol $(3 \mu \mathrm{g} / \mathrm{kg})$ or vehicle had no effect on arterial blood $\mathrm{pH}, \mathrm{PO}_{2}, \mathrm{PCO}_{2}$, and hemoglobin in either maternal or fetal animals (Table 1). These arterial values were not significantly different between the control and the experimental groups (all $p>0.05$ ).

\section{Cardiovascular Responses}

Histological analysis confirmed that all i.c.v. cannulae were inserted into the fetal lateral ventricle. There was no significant difference between the control and experimental groups for maternal systolic pressure, diastolic pressure, and MAP (all $p>0.05$ ). However, i.c.v. injection of carbachol $(3 \mu \mathrm{g} / \mathrm{kg})$ into the fetus significantly increased fetal BP (Table 1). Fetal systolic and diastolic pressure, and MAP were increased in the experimental group as compared to the control fetuses $\left(\mathrm{F}_{8,1}=25.9,19.2\right.$, and 9.1, respectively, $p<0.01)$. In the experimental animals, fetal MAP was increased from the baseline level, $43.9 \pm 1.1 \mathrm{mmHg}$, to $66.5 \pm 2.2 \mathrm{mmHg} 30 \mathrm{~min}$ after i.c.v. injection of carbachol $(p<0.01)$. This was $51.5 \%$ increase from the baseline MAP. The latency of the pressor response was within $2 \mathrm{~min}$. The increased MAP lasted for more than 90 min (Figure 1 and Table 1). In the control animals, i.c.v. injection of vehicle had no effect on fetal systolic and diastolic pressure, and MAP in the near-term fetus (all $p>0.05$ ).

Table I Maternal (Upper Panel) and Fetal (Lower Panel) Cardiovascular Responses and Arterial Values before and after Central Carbachol $(3 \mu \mathrm{g} / \mathrm{kg})$ Injection in Fetuses

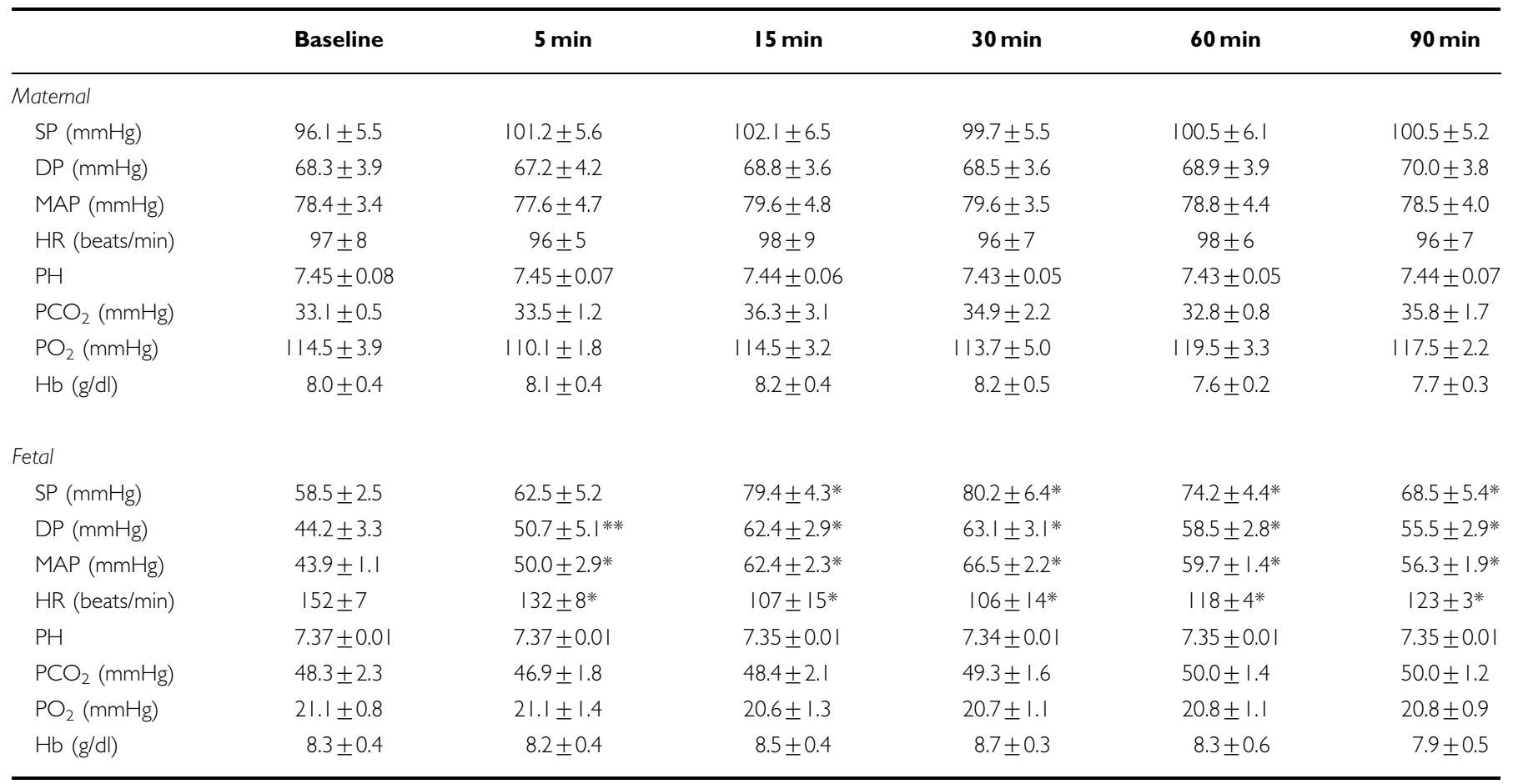

Values are mean \pm SEM. ${ }^{*} p<0.0$ I; ** $p<0.05$, compared with the baseline level. SP, systolic pressure; DP, diastolic pressure; MAP, mean arterial pressure; HR, heart rate. $\mathrm{Hb}$, hemoglobin. 


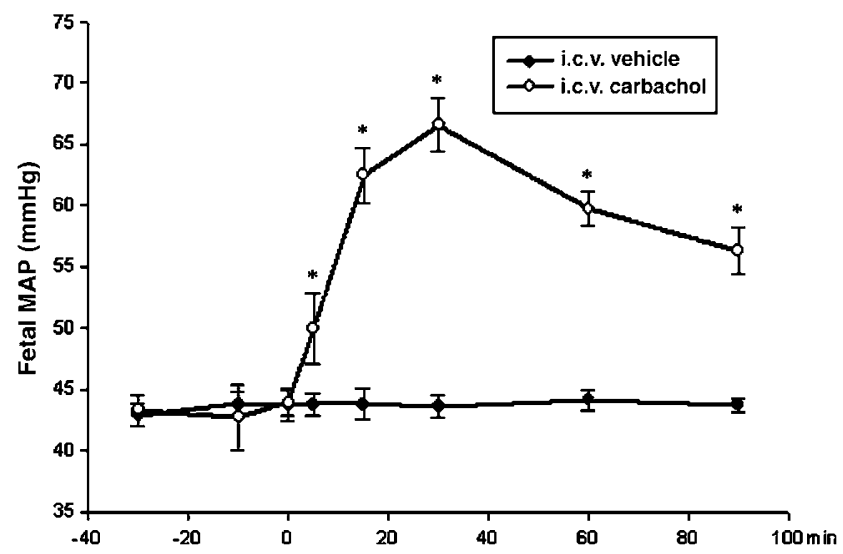

Figure I Effect of i.c.v. injection of carbachol $(3 \mu \mathrm{g} / \mathrm{kg})$ on fetal MAP $(\mathrm{mmHg}) .0 \mathrm{~min}$ : time for i.c.v. injection. ${ }^{*} p<0.01$, compared with the baseline level. i.c.v. intracerebroventricular; MAP, mean arterial pressure.

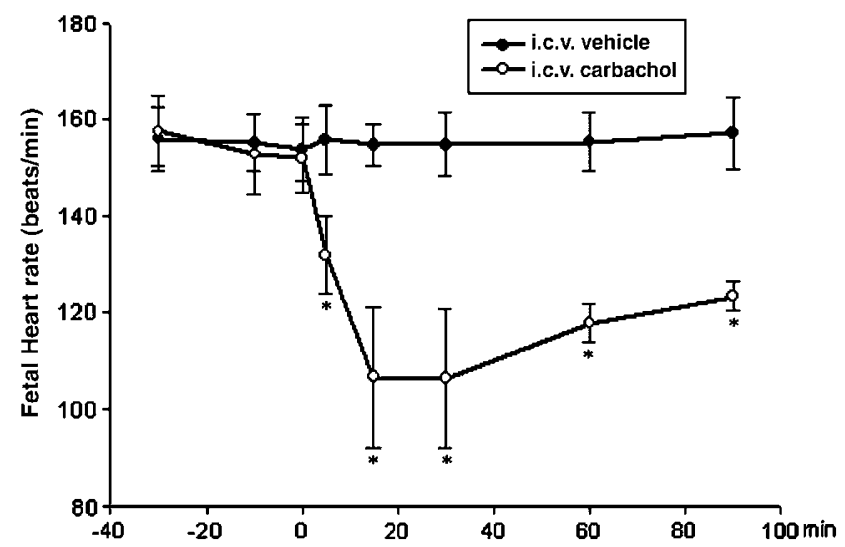

Figure 2 Effect of i.c.v. injection of carbachol $(3 \mu \mathrm{g} / \mathrm{kg})$ on fetal heart rate. 0 min: time for i.c.v. injection. ${ }^{*} p<0.0$ I, compared with the baseline level. i.c.v., intracerebroventricular.

Maternal heart rate was not changed by the i.c.v. injection of carbachol into the fetus $(p>0.05)$ (Table 1). However, a bradycardia was induced in the fetuses by the central administration of carbachol (Figure 2). The maximum decrease of fetal heart rate was observed at $30 \mathrm{~min}$ after the i.c.v. injection ( $\Delta$ heart rate $=46$ beats $/ \mathrm{min})$.

\section{FOS Immunoreactivity}

There was little or no FOS-ir in the fetal forebrain in the control group. However, after the i.c.v. injection of carbachol, there was intense staining of FOS-ir in the AV3V region, including the OVLT and the MnPO (both dorsal and ventral regions) (Figures 3 and 4). There were significant differences of FOS-ir between i.c.v. vehicle- and i.c.v. carbachol-injected fetuses (OVLT: $t=10.7$; dorsalMnPO: $t=5.4$; ventral-MnPO: $t=4.5$, all $p<0.01$, Figures 3 and 4). In the hindbrain, none or very little FOS-ir was observed in the AP, NTS, LPBN, and RVLM in the control animals injected with the vehicle. However, i.c.v. carbachol induced positive FOS-ir in these structures (AP: $t=4.7$;

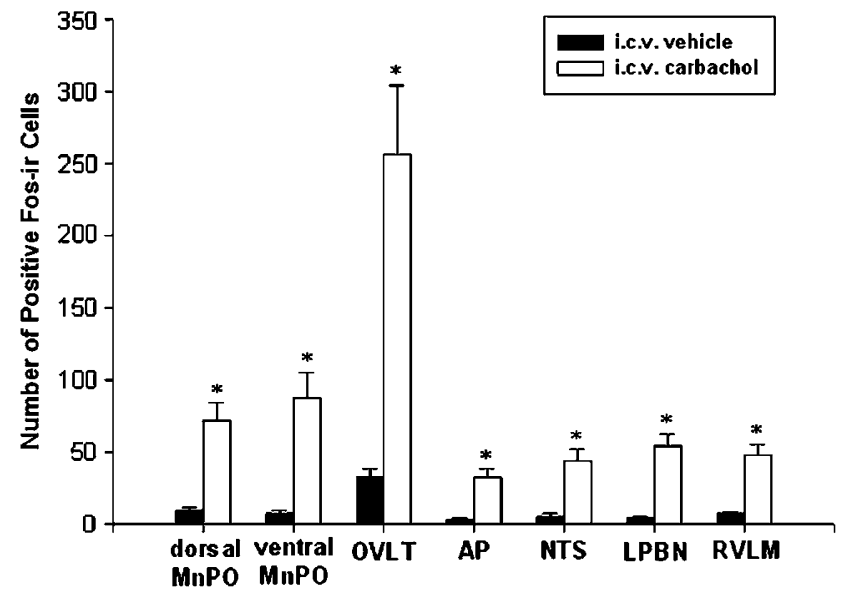

Figure 3 Effect of i.c.v. injection of carbachol $(3 \mu \mathrm{g} / \mathrm{kg})$ on FOS-ir in the fetal brain. ${ }^{*} p<0.01$ compared with the control level. i.c.V., intracerebroventricular; $\mathrm{MnPO}$ median preoptic nucleus; OVLT, organum vasculosum of the lamina terminalis; AP, area postrema; NTS, nucleus tractus solitary; LPBN, lateral parabrachial nuclei; RVLM, rostral ventrolateral medulla.
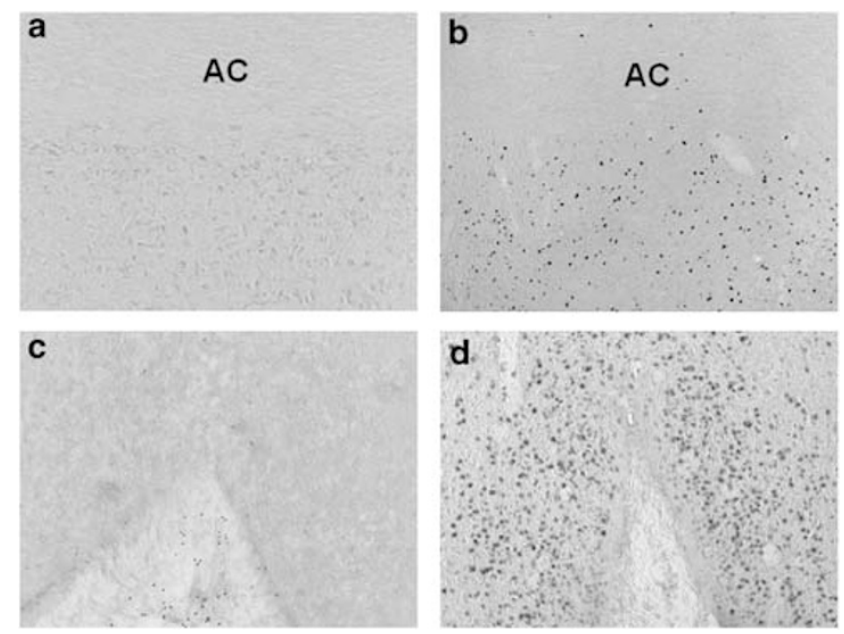

Figure 4 FOS-ir induced by i.c.v. carbachol in the fetal MnPO and OVLT. MnPO (upper panel) and OVLT (bottom panel). (a, c) Animal treated with i.c.v. vehicle; (b, d) Animal injected with i.c.v. carbachol $(3 \mu \mathrm{g} / \mathrm{kg})$. AC, anterior commissure. Magnification: $\times 10$.

NTS: $t=10.9$; LPBN: $t=4.4$; RVLM: $t=10.2$, all $p<0.01$, Figures 3 and 5).

\section{DISCUSSION}

The present study demonstrated that i.c.v. application of carbachol not only produced pressor responses in the nearterm ovine fetus but also increased the neural activity in the putative central cardiovascular controlling centers. The finding that $\mathrm{c}$-fos expression was induced in the fetal AV3V and the hindbrain is the evidence that the central pathway are activated and cholinergic mechanisms are functional in the control of fetal blood pressure at $90 \%$ gestation, and indicates that the fetal AV $3 \mathrm{~V}$ region in the forebrain and 
a
NTS

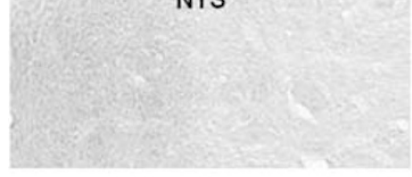

C $\mathrm{scp}$ b NTS

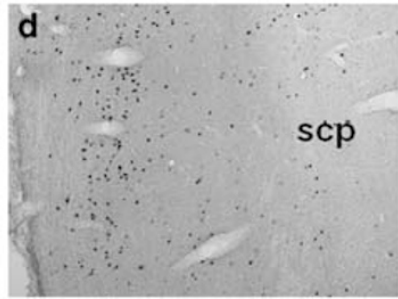

Figure 5 FOS-ir induced by i.c.v. carbachol in the fetal NTS and LPBN NTS (upper panel) and LPBN (bottom panel). (a, c) Animal treated with i.c.v. vehicle; (b, d) Animal injected with i.c.v. carbachol (3 IOg/ $/ \mathrm{kg}$ ). Scp, superior cerebellar peduncle. Magnification: $\times 10$

specific nuclei in the hindbrain have developed well in response to cholinergic stimulation.

In mature animals, carbachol is known as a long-lasting cholinergic agonist in the brain in affecting body fluid and cardiovascular homeostasis, including increase of arterial blood pressure, release of vasopressin, and stimulation of thirst (Barbosa et al, 1995; Iitake et al, 1986; Mahon et al, 1995; Poole, 1983). Previous studies in adults showed that the pressor response induced by central administered carbachol was marked and sustained with short latency (Poole, 1983; Özkutlu et al, 1994). In the present study, consistent with the results in adults, the onset of the central carbachol-induced pressor responses in fetuses was rapid. The fetal systolic pressure, diastolic pressure, and MAP significantly increased within 2 min after i.c.v. injection of this cholinergic receptor agonist. The MAP reached its peak $30 \mathrm{~min}$ after the injection. Moreover, the increased fetal systolic, diastolic, and MAP maintained at a high level for more than $90 \mathrm{~min}$. Accompanied with the increase of BP, the fetal heart rate decreased, which was also similar to that of the adults (Imai et al, 1989). In the present study, the fetal heart rate decreased immediately after the i.c.v. injection of carbachol, and the maximum decrease was observed at $30 \mathrm{~min}$ after the central carbachol administration. Earlier autoradiographic study has shown that an active cholinergic system is present in the fetus (Kinney et al, 1993, 1995). The present study demonstrates that the cholinomimetic agent carbachol in the fetal brain could produce a long-lasting pressor and bradycardia response. These results provide new evidence that the brain cholinergic system in the nearterm fetus is relatively intact and functional in the control of cardiovascular functions.

Several lines of evidence showed that multiple sites in the CNS play a role in cholinergically mediated changes, and that the changes in BP by centrally administered cholinergic agonists are site-specific. Previous studies by us and others have shown c-fos expression patterns following i.c.v. injection of carbachol in adult rats (Mahon et al, 1995; Xu et al, 2001b). Forebrain sites, particularly those located in the $\mathrm{AV} 3 \mathrm{~V}$ region (specially the $\mathrm{MnPO}$ and the OVLT), are the major structures mediating the responses to central carbachol (Fuller, 1984; Johnson and Thunhorst, 1997; Menani et al, 1990). To determine central actions of carbachol in the fetal brain, a c-fos-mapping technique was employed in this investigation. C-fos is a member of a family of proto-oncogenes that show transcriptional activation by a variety of stimuli. The protein product of this gene can be readily detected and widely used as a spatially and temporally specific indicator of neuronal activation (Curran and Morgan, 1987; Morgan and Curran, 1990). Therefore, correlating the $\mathrm{c}$-fos expression in the brain in response to central administration carbachol may aid in elucidating the neural substrates involved.

In the present study, the pattern of c-fos after i.c.v. carbachol was generally consistent with findings in adult models (Mahon et al, 1995; Rowland et al, 1994). The anterior wall of the third ventricle, particularly the MnPO (both dorsal and ventral division) and OVLT, contains intense FOS-positive cells in all fetuses injected with i.c.v. carbachol but not in fetuses treated with i.c.v. vehicle. It is known that the OVLT and MnPO are pivotal components of the lamina terminalis that forms the anterior wall of the third ventricle and, via the intraventricular foramen, accessible to injection of carbachol into the lateral ventricle. Since FOS-ir indicates increased neural activity (Dragunow and Faull, 1989; Morgan et al, 1987), it seems likely that i.c.v. injection of carbachol stimulated neurons in the AV3V region by action on specific acetylcholine receptors.

Many studies on adult models demonstrated that the $\mathrm{AV} 3 \mathrm{~V}$ region is an important integrative site for $\mathrm{BP}$ regulation (Brody et al, 1978; Brody and Johnson, 1980). Lesions of this area, including the ventral MnPO, abolish carbachol-induced pressor responses (Menani et al, 1990; Colombari et al, 1992). Of the nuclei located in the AV3V region, the OVLT is what has been termed the sensory circumventricular organ (Johnson and Gross, 1993). This periventricular structure is generally recognized for its important role in monitoring indexes of body fluid homeostasis. The OVLT and the MnPO are vital components of a central neural network that is essential for normal body fluid and cardiovascular homeostasis (Oldfield et al, 1994). Efferents from the OVLT project to the hypothalamic structures and the dorsal and ventral MnPO. Moreover, the MnPO receives afferents not only from the OVLT but also from a variety of structures, including the paraventricular nucleus of the hypothalamus, the parabrachial nucleus, the nucleus of the solitary tract, and the ventrolateral medulla, which have been implicated in cardiovascular regulation (Saper and Levisohn, 1983). Therefore, the induced c-fos expression in $\mathrm{MnPO}$ in this study is presumed to result from direct stimulation by i.c.v. carbachol, and/or inputs from other structures of the brain. It is certain that the increased FOS-ir in the MnPO and OVLT indicates that the cholinergic system located in the fetal AV3V region has been well developed to respond to the cholinergic stimulation.

In comparison to the numerous studies of cholinergic mechanism-mediated cardiovascular responses in the forebrain, studies about the roles of the hindbrain in cholinergic-associated cardiovascular regulation have received little attention. However, in recent years, it has been 
demonstrated that a relatively high density of cholinergic receptors are located in the brain stem of both adults and fetuses (Gurtu et al, 1986; Kinney et al, 1993, 1995; Sundaram and Sapru, 1988; Willette et al, 1984). Furthermore, accumulating evidence suggest that cholinergic mechanisms in the specific hindbrain nuclei are involved in central regulation of BP (Gurtu et al, 1986; Sundaram and Sapru, 1988; Willette et al, 1984).

In the present study, accompanied by the central carbachol-induced pressor response, the fetal heart rate was decreased. FOS-staining studies showed that c-fos expression was significantly increased in the fetal AP, NTS, LPBN, and RVLM in the hindbrain. Since hypoxia could cause FOS-ir in the brain stem in fetal sheep (Breen et al, 1997; Nitsos and Walker, 1999), the fetal blood gas analysis showed that neither $\mathrm{PO}_{2}$ nor $\mathrm{PCO}_{2}$ was changed by the central carbachol. In addition, fetal blood $\mathrm{pH}$ and hemoglobin was not altered after i.c.v. injections. These results suggest that the oxygenation condition was stable during the study and FOS-ir in the brain stem was not due to nonspecific responses.

An acute increase of BP will allow the baroreflex control of the heart rate under certain conditions. Moreover, c-fos expression induced by increased BP and/or baroreflex is mainly located in the hindbrain, particularly, in the NTS, the LPBN, and the RVLM (Chan and Sawchenko, 1998; Jhamandas et al, 1998; Williams et al, 2000). In this investigation, combining the functional responses with the neural reaction, it is reasonable to conjecture that the bradycardia was due to, mainly or partially, a baroreflex response subsequent to the acute increase of arterial pressure induced by i.c.v. carbachol.

It is known that the NTS and the AP are the essential central areas of the baroreflex. Neural afferents from arterial and cardiac baroreceptors terminate in the NTS and in portions of the AP (Bradd et al, 1989). Anatomical observations showed that efferents from the AP and NTS project to the LPBN (Lanca and van der Kooy, 1985). Therefore, the intense FOS-ir in the AP/NTS/LPBN induced by central carbachol is presumably due to (1) direct stimulation of these nuclei by i.c.v. carbachol and/or (2) the baroreflex activation is subsequent to the pressor response following central carbachol. Regardless of which mechanism is the primary factor, the c-fos expression in the hindbrain strongly suggests that the fetal AP/NTS/LPBN systems can be activated in response to central cholinergic stimulation and in association with cardiovascular changes before birth.

This is the first study on central cholinergic actions and cardiovascular regulation in utero. The results reveal the functional development of the central cholinergic systems in association with cardiovascular controlling at near-term. Importantly, the present study provides evidence that the putative cardiovascular controlling centers, especially critical areas in the region of AV3V and the hindbrain, are functional in the last third of gestation. It is apparent that central cholinergic systems have been well developed in the control of fetal blood pressure before birth. The results gained increase the understanding of ontogeny of brain cholinergic mechanisms in cardiovascular regulation. This not only provides evidence of the functional development of brain cholinergic systems at $90 \%$ gestation in sheep but also offers an opportunity for further investigation of mechanisms that may influence the development of fetal central cholinergic systems in light of prenatal impacting on postnatal health problems.

\section{ACKNOWLEDGEMENTS}

These studies were supported by March of Dimes Research Grant, External Research Grant from Philip Morris USA Inc., UCLA Faculty Grant Program Award, and Soochow University fund.

\section{REFERENCES}

Barbosa SP, de Gobbi JI, Zilioli L, Camargo LA, Saad WA, Renzi A et al (1995). Role of cholinergic and adrenergic pathways of the medial septal area in the water intake and pressor response to central angiotensin II and carbachol in rats. Brain Res Bull 37: 463-466.

Bradd J, Dubin J, Due B, Miselis RR, Montor S, Rogers WT et al (1989). Mapping of carotid sinus inputs and vagal cardiac outputs in the rat. Soc Neurosci Abstr 15: 593.

Breen S, Rees S, Walker D (1997). Identification of brainstem neurons responding to hypoxia in fetal and newborn sheep. Brain Res 748: 107-121.

Brezenoff HE, Giuliano R (1982). Cardiovascular control by cholinergic mechanisms in the central nervous system. Ann Rev Pharmacol Toxicol 22: 341-381.

Brody MJ, Fink GD, Buggy J, Haywood JR, Gordon FJ, Johnson AK (1978). The role of the anteroventral third ventricle (AV3V) region in experimental hypertension. Circ Res 43(Suppl I): I-1I-13.

Brody MJ, Johnson AK (1980). Role of the anteroventral third ventricle region in fluid and electrolyte balance, arterial pressure regulation and hypertension. In: Martini L, Ganong WF (eds). Frontiers in Endocrinology Vol. 6. Raven: New York. pp 249-292.

Chan RK, Sawchenko PE (1998). Organization and transmitter specificity of medullary neurons activated by sustained hypertension: implications for understanding baroreceptor reflex circuitry. J Neurosci 18: 371-387.

Colombari DS, Saad WA, Camargo LA, Renzi A, De Luca Jr LA, Colombari E et al (1992). AV3V lesion impairs responses induced by cholinergic activation of SFO in rats. Am J Physiol 263: R1277-R1283.

Curran T, Morgan JI (1987). Memories of fos. BioEssays 7: 255-258.

Dragunow M, Faull R (1989). The use of c-fos as a metabolic marker in neuronal pathway tracing. J Neurosci Methods 29: 261-265.

Fitzsimons JT (1972). Thirst. Physiol Rev 52: 468-561.

Fuller LM (1984). The pharmacology of drinking behavior. Pharmacol Ther 24: 179-206.

Grossman JP (1960). Eating and drinking elicited by direct adrenergic or cholinergic stimulation of the hypothalamus. Science 132: 301-302.

Gurtu S, Sharma DK, Pant KK, Sinha JN, Bhargava KP (1986). Role of medullary choloinoceptors in baroreflex bradycardia. Clin Exp Hypertens A 8: 1063-1079.

Hoffman WE, Philips MI, Schmid PG, Falcon J, Weet JF (1977). Antidiuretic hormone release and the pressorresponse to central angiotensin II and cholinergic stimulation. Neuropharmacology 16: $463-472$.

Iitake K, Share L, Ouchi Y, Crofton JT, Brooks DP (1986). Central cholinergic control of vasopressin release in conscious rats. $\mathrm{Am}$ J Physiol 251: E146-E150. 
Imai Y, Abe K, Sasaki S, Minami N, Munakata M, Yumita S et al (1989). Role of vasopressin in cardiovascular response to central cholinergic stimulation in rats. Hypertension 13: 549-557.

Jhamandas JH, Harris KH, Petrov T, Yang HY, Jhamandas KH (1998). Activation of neuropeptide FF neurons in the brainstem nucleus tractus solitarius following cardiovascular challenge and opiate withdrawal. J Comp Neurol 14: 210-221.

Johnson AK, Gross PM (1993). Sensory circumventricular organs and brain homeostatic pathways. FASEB J 7: 678-686.

Johnson AK, Thunhorst RL (1997). The neuroendocrinology of thirst and salt appetite: visceral sensory signals and mechanisms of central integration. Front Neuroendocrinol 18: 292-353.

Kinney HC, O'Donnell TJ, Kriger P, White WF (1993). Early developmental changes in $[3 \mathrm{H}]$ nicotine binding in the human brainstem. Neuroscience 55: 1127-1138.

Kinney HC, Panigrahy A, Rava LA, White WF (1995). Threedimensional distribution of $[3 \mathrm{H}]$ quinuclidinyl benzilate binding to muscarinic cholinergic receptors in the developing human brainstem. J Comp Neurol 362: 350-367.

Kubo T, Ishizuka T, Asari T, Fukumori R (1995). Acetylcholine release in the rostral ventrolateral medulla of spontaneously hypertensive rats. Clin Exp Pharmacol Physiol 22: S40-S42.

Lanca AJ, van der Kooy D (1985). A serotonin-containing pathway from the area postrima to the parabrachial nucleus in the rat. Neuroscience 14: 1117-1126.

Mahon JM, Allen M, Herbert J, Fitzsimons JT (1995). The association of thirst, sodium appetite and vasopressin release with c-fos expression in the forebrain of the rat after intracerebroventricular injection of angiotensin II, angiotensin(1-7) or carbachol. Neuroscience 69: 199-208.

Menani JV, Saad WA, Camargo LAA, Renzi A, De Luca Jr LA, Colombari E (1990). The anteroventral third ventricle (AV3V) region is essential for pressor, dipsogenic and natriuretic responses to central carbachol. Neurosci Lett 113: 339-344.

Morgan JI, Cohen DR, Hempstead JL, Curran T (1987). Mapping patterns of c-fos expression in the central nervous system after seizure. Science 237: 192-197.

Morgan JI, Curran T (1990). Inducible protooncogenes of the nervous system - their contribution to transcription factors and neuroplasticity. Prog Brain Res 86: 287-294.

Nawayhid B, Brinkman CR, Su C, Bevan JA, Assali NS (1975). Systemic and pulmonary hemodynamic responses to adrenergic and cholinergic agonists during fetal development. Biol Neonate 26: $301-317$.

Nitsos I, Walker DW (1999). The distribution of FOS-immunoreactive neurons in the brainstem, midbrain and diencephalon of fetal sheep in response to acute hypoxia in mid and late gestation. Brain Res Dev Brain Res 114: 9-26.

Oldfield BJ, Badoer E, Hards DK, McKinley MJ (1994). Fos production in retrogradely labelled neurons of the lamina terminalis following intravenous infusion of either hypertonic saline or angiotensin II. Neuroscience 60: 255-262.
Onal A, Uysal A, Ulker S, Delen Y, Yurtseven ME, Evinc A (2004). Alterations of brain tissue in fetal rats exposed to nicotine in utero: possible involvement of nitric oxide and catecholamines. Neurotoxicol Teratol 26: 103-112.

Oncken CA, Henry KM, Campbell WA, Kuhn CM, Slotkin TA, Kranzler HR (2003). Effect of maternal smoking on fetal catecholamine concentrations at birth. Pediatr Res 53: 119-124.

Özkutlu U, Coskun T, Onat F, Yegen BC, Oktay S (1994). Cardiovascular effects of centrally active cholinomimetics in conscious and anesthetized rats: the role of amygdale. Brain Res Bull 37: 569-573.

Poole S (1983). Cardiovascular responses of rats to intrahypothalamic injection of carbachol and noradrenaline. Br J Pharmacol 79: 693-700.

Robillard JE, Matson JR, Sessions C, Smith FG (1979). Development aspects of renal tubular reabsorption of water in the lamb fetus. Pediatr Res 13: 1172-1176.

Rowland NE, Li BH, Rozelle AK, Smith GC (1994). Comparison of Fos-like immunoreactivity induced in rat brain by central injection of angiotensin II and carbachol. Am J Physiol 36: R792-R798.

Saper CB, Levisohn D (1983). Afferent connections of the median preoptic nucleus in the rat: anatomical evidence for a cardiovascular integrative mechanism in the anteroventral third ventricular (AV3V) region. Brain Res 288: 21-31.

Stone JD, Crofton JT, Share L (1992). Sex differences in central cholinergic and angiotensinergic control of vasopressin release. Am J Physiol 263: R1030-R1034.

Sundaram K, Sapru H (1988). Cholinergic nerve terminals in the ventrolateral medullary pressor area: pharmacologic evidence. J Auton Nerv Syst 22: 221-228.

Szeto HH, Hinman DJ (1990). Central muscrinic modulation of fetal blood pressure and heart rate. J Dev Physiol 13: $17-23$.

Vehaskari VM, Aviles DH, Manning J (2001). Prenatal programming adult hypertension in the rat. Kidney Int 59: 238-245.

Willette RN, Punnen S, Krieger AJ, Sapru HN (1984). Cardiovascular control by cholinergic mechanisms in the rostral ventrolateral medulla. J Pharmacol Exp Ther 231: 457-463.

Williams CA, Loyd SD, Hampton TA, Hoover DB (2000). Expression of $\mathrm{c}$-fos-like immunoreactivity in the feline brainstem in response to isometric muscle contraction and baroreceptor reflex changes in arterial pressure. Brain Res 852: 424-435.

Xu Z, Calvario G, Yao J, Day L, Ross MG (2001a). Central angiotensin induction of fetal brain c-fos expression and swallowing activity. Am J Physiol 280: R1837-R1843.

$\mathrm{Xu}$ Z, Ross MG, Johnson AK (2001b). Intracerebroventricular carbachol induces FOS immunoreactivity in lamina terminalis neurons projecting to the supraoptic nucleus. Brain Res 895: 104-110. 